\title{
Tendencias investigativas sobre la narración oral en la escuela. (2009-2014)*
}

Research trends on oral storytelling at school. (2009-2014)

Tendências investigativas sobre

a narração oral na escola. (2009-2014)

Recibido el 3 de diciembre de 2014. Aceptado el 23 de abril de 2015

Para citar este artículo:

López de Parra, Lillyam, Pérez

Ramirez, Luis Guillermo,

Ramírez Calderón, Bárbara

Julieth (2015). Tendencias

investigativas sobre la narración

oral en la escuela (2009-2014).

Ánfora, 22 (38), 163 -190.

Universidad

Autónoma de Manizales. ISSN

0121-6538

\author{
Lillyam López de Parra** \\ Colombia \\ Luis Guillermo Pérez Ramirez ** \\ Colombia \\ Bárbara Julieth Ramírez Calderón ** \\ Colombia
}

\section{Resumen}

Objetivo: identificar las tendencias de las investigaciones relacionadas con la narración oral en el entorno escolar, durante los últimos cinco años, en diversos países de habla hispana Metodología: estudio de carácter documental con enfoque cualitativo. En esta Revisión se describió y analizó el desarrollo de la investigación sobre la narración oral en la escuela, durante los últimos cinco años. Se desarrolló

\footnotetext{
* Artículo derivado de la investigación en proceso "La narración oral en los estudiantes del grado sexto de la Institución Educativa Antonio Ricaurte; estrategias didácticas para su desarrollo".

** Doctora en Educación. Profesora e investigadora de la Universidad de la Amazonia, Florencia, Caquetá. Correo electrónico: lillyamlopez@yahoo.es y mar.lopez@udla.edu.co

** Estudiante del Programa de Lengua castellana y literatura de la Universidad de la Amazonia. Florencia Caquetá. Correo electrónico: memotil99@gmail.com

** Estudiante del Programa de Lengua castellana y literatura de la Universidad de la Amazonia. Florencia Caquetá. Correo electrónico:barbarajuilethramirezcalderon@gmail.com
} 
en dos fases: heurística y hermenéutica. Las categorías de búsqueda fueron: narración oral en la escuela, narración oral, investigaciones narración oral. Se consultaron varias bases de datos electrónicas. El instrumento fue una base de datos. Resultados: se encontró que en cuanto a las temáticas las principales tendencias fueron: relación entre narración oral y el cuento (estrategia didáctica, cultura, la identidad, intervención social y lo escénico); la didáctica; aplicación en ambientes educativos; aspectos gramaticales; historia y tradición oral; competencias comunicativas y educación especial. La tendencia del enfoque metodológico es el cualitativo y la utilización de técnicas como la observación, entrevista y revisión documental. Los temas novedosos o emergentes son las TIC; la discapacidad en relación con la narración oral. Conclusiones: Colombia, España y Venezuela son los países que han sobresalido por la producción investigativa en el campo En los trabajos analizados. Hay interés por analizar la narración oral desde diversas perspectivas. Sin embargo, se carece de investigación acerca de la formación del profesor y la reflexión pedagógica y didáctica para la su inclusión de manera transversal en los currículos escolares.

Palabras clave: Narración oral, Educación, Escuela, Acto artístico, Estrategia didáctica.

\section{Abstract}

Objective: to identify trends in research regarding oral storytelling in the school environment carried out during the past five years in various Spanish-speaking countries. Methodology: documentary study with qualitative approach. In this review, the development of the research on oral storytelling at school, during the past five years, was described and analyzed. It was developed in two phases: heuristic and hermeneutic. The search categories were: oral storytelling at school, oral storytelling and oral storytelling research. Several electronic databases were consulted. The instrument used was a data collection sheet and a database was created. Results: the main trends found were: relation between oral storytelling and tale (teaching strategy, culture, identity, social intervention and scenic aspects), didactics, application in educational settings, grammar issues, history and oral tradition, communication skills and special education. The methodology had a qualitative approach and techniques such as observation, interviews and document review were used. The new or emerging topics are ICT and disability in relation to oral storytelling. Conclusions: Colombia, Spain and Venezuela have excelled by their research production in this field according to the analyzed studies. There is an interest in analyzing oral storytelling from various perspectives. However, there is a lack of research on teacher training as well as on pedagogical and didactic reflection for its transversal inclusion in school curricula.

Keywords: Oral storytelling, Education, School, Artistic act, Didactic strategy 


\section{Resumo}

Objetivo: identificar as tendências das pesquisas relacionadas ànarração oral no ambiente escolar, ao longo dos últimos cinco anos em vários países hispânicos. Metodologia: estudo de caráter documental com abordagem qualitativa. Em esta revisão descreveu-se e analisouse o desenvolvimento da pesquisa sobre a narração oral na escola, durante os últimos cinco anos. Elefoi desenvolvido em duas fases: heurística e hermenêutica. As categorias de pesquisa foram: narração oral na escola, narração oral, pesquisas de narração oral. Consultaram-se várias bases de dados eletrônicas. $O$ instrumento foi ficha de colheita de informação e se construiu uma base de dados. Resultados: as principais tendências encontradas foram: relação entre narração oral e o conto (Estratégia didática, cultura, a identidade, intervenção social e o cênico); a didática; aplicação em contextos educativos; aspetos gramaticais; história e tradição oral; competências comunicativas e educação especial. A tendência da abordagem metodológica é a qualitativa e o uso de técnicas como a observação, entrevista e revisão documental. As temáticas novas ou emergentes são as TIC; a deficiência em relação à narração oral. Conclusões: Colômbia, Espanha e Venezuela são os países que se destacaram pela produção de investigação no campo nos trabalhos analisados. Há interesse em analisar a narração oral a partir de várias perspectivas. No entanto, há uma falta de investigação sobre a formação de professores e a reflexão pedagógica e didática para sua inclusão de um jeito transversal nos currículos escolares.

Palavras-chave: Narração oral, Educação, Escola, Ato artístico, Estratégia didática. 


\section{Introducción}

La narración oral es un concepto complejo dado que puede tener relación con: a) la conducta expresivo-comunicadora del ser humano que tiene su origen en la necesidad de comunicación y expresada en la conversación "que contiene al acto no artístico de narrar oralmente; y en el ámbito íntimo que propicia y define a las conversaciones" (Garzón, 2008, p.1); b) el arte del cuentero de hechos de la cotidianidad sin intención artística; c) la narración oral artística del contador de cuentos cercanos a la literatura, a la docencia y a la promoción del libro; d) La narración oral artística es el arte del narrador oral escénico:

La narración oral es el arte de este narrador oral escénico que puede contar un mito, una leyenda, una anécdota, un relato, un cuento, una novela, entre más, porque puede hacerlos suyos con el niño, con el joven, con el adulto, cada uno como tal, o con todos a la vez en cualquier espacio posible, para reinventarlos como maravilla creadora. (Garzón, 2008, p. 2).

Todas las definiciones se relacionan con la comunicación, la conversación, relato, la viva voz y todo el cuerpo, la interacción, el público (considerado interlocutor), la influencia recíproca, la creatividad la cultura, el contexto y la fantasía, todos estos conceptos confluyen en su definición:

La narración oral es un acto de comunicación donde el ser humano, al narrar a viva voz y con todo su cuerpo, con el público y no para el público, crea un proceso de interacción en el cual emite un mensaje y recibe respuesta, por lo que no se informa si no que comunica pues, influye y es influenciado, en el instante mismo de narrar, para que el cuento oral crezca con todos y de todos, entre todos (Garzón, 1991, p.68).

Se reitera la narración oral como comunicación: "la narración oral antes de convertirse en narración oral escénica, es una conducta expresiva comunicadora (verbal, vocal, sonora y no verbal) que se manifiesta en forma de conversación entre niños, niñas, jóvenes y adultos" (Garzón, 1998, pp. 45-46). Del mismo modo, Barba (2012), plantea que las dinámicas para abordar el análisis de la narración oral deben ser comprendidas como una totalidad, no desde la individualidad del narrador, sino desde unas situaciones comunicativas en proceso de interacción social. Otros, la asumen como: "la actividad de contar los cuentos en voz alta" (Tejerina, 2010, p. 51); al incluir el cuento, se resalta la característica de lo estético. Asimismo, se considera a la narración oral como acto de interacción y herramienta comunicativa de mucha ayuda para los profesores y estudiantes en su proceso enseñanza-aprendizaje (Rael, 2009). 
Por esta razón, la narración oral de cuentos, es hoy por hoy, una de las herramientas didácticas más efectivas para mejorar en los y las estudiantes su competencia comunicativa. De acuerdo con Rael (2009) la narración oral en la escuela tiene diversas funciones, entre otras, el enriquecimiento del patrimonio lingüístico, el espíritu crítico, el aumento de la imaginación, el desarrollo de la fantasía, el cultivo de sentimientos y la ayuda a la asimilación crítica de la información. De ahí, la necesidad de resaltar el mundo de las palabras que narran, dicen y recrean el universo porque escriben y registran la experiencia diaria de la vida en el aula (Zerpa, 2012).

Los profesores buscan mejorar las propuestas de enseñanza y aprendizaje en los educandos a través de la narración oral aunque, poco se conocen los aportes investigativos que fundamenten su práctica en las instituciones educativas. Conviene subrayar que desde hace por lo menos 30 años, la narración oral en Colombia ha atravesado un proceso de consolidación. En el transcurso de este tiempo, un grupo de autores, investigadores y académicos han buscado un rumbo que les permita tener un marco teórico para contribuir al fortalecimiento de la narración oral, tanto en las instituciones educativas, como en la sociedad.

La perspectiva, es trabajar la oralidad en la escuela como un elemento de desarrollo del habla en los primeros años de escolaridad. Se puede asumir que los niños y niñas están en condiciones de usar la lengua oral para vincularse, dentro y fuera de su aula escolar, a diferentes tipos de interacciones. Es importante resaltar su relación con el mundo de las fabulas, mitos, leyendas y cuentos. Desde esta posición didáctica, los y las estudiantes se pueden apropiar de la capacidad de contar no solamente estos textos; también lo ocurrido en la vida cotidiana. Fernández (2012) propone hacer relatos orales, escritos, tomar imágenes fijas y en movimiento o interactuar por medio de las conversaciones reflexivas. Igualmente, dejar que ellos, a partir de la anécdota e imágenes, planten situaciones de vida.

La narración oral, cobra importancia dado que responde a innumerables necesidades relacionadas con la interacción social del ser humano; recrea las palabras y procura que éstas puedan construir una situación discursiva. En este sentido, es un mundo de palabras y sonidos que el niño comienza a identificar y a regalar con las mejores palabras a quien lo escucha (Rael, 2009).

No obstante, el valor de la narración oral en la escuela, se desconocen los desarrollos investigativos sobre esta temática, durante los últimos cinco años; asimismo, no hay un conocimiento acerca de los enfoques teóricos y 
metodológicos y de los resultados de la investigación para que los profesores tomen los aportes para implementar la narración oral como estrategia didáctica. Esto se evidencia porque la narración oral en la escuela no se reconoce como un elemento de comunicación (Barba, 2012; Valbuena, 2012; Tamayo, López y Torres, 2012; Fernández, 2012 y Sbriziolo, 2013). De ahí el interés por resolver el interrogante: ¿cuál es el desarrollo de la investigación en la narración oral en la escuela, durante los últimos cinco años?

Para resolver la pregunta formulada, el objetivo de este trabajo es describir y analizar el desarrollo de la investigación en la narración oral en la escuela, durante los últimos cinco años. Se trata de dar cuenta de las tendencias investigativas de la narración oral.

Una tendencia se entiende como una preferencia, inclinación o predilección hacia un determinado fin. Dar cuenta de las tendencias investigativas acerca de la narración oral es fundamental porque posibilita presentar una visión de los enfoques teóricos y metodológicos empleados en las investigaciones y analizar sus principales resultados. Esta reflexión aporta elementos para la inclusión de la narración oral en las prácticas comunicativas del aula. Además, puede propiciar el interés investigativo de los académicos y en particular, de los profesores, para realizar procesos reflexivos y sistematizados acerca del fomento de la narración oral.

\section{Metodología}

Se recurrió al proceso de investigación documental con un enfoque cualitativo. Se desarrolló en dos fases: heurística y hermenéutica. En la primera, se seleccionó y delimitó la temática de indagación, en este caso, la narración oral en la escuela como una de las líneas de la oralidad. Las categorías de búsqueda de los documentos fueron: narración oral en la escuela, narración oral, investigaciones narración oral. También, se definieron los siguientes criterios de selección de la información: a) documentos resultados de investigación presentados en artículos, ponencias, tesis de grado, maestría o doctorado; b) publicados durante los últimos cinco años (2009-2014) y c) relacionados con el tópico de indagación.

Luego, se averiguó la información en diversas bases de datos (Google académico, Cedoc, Redalyc, Scielo).Se consultaron diversos tipos de documentos entre ellos: 28 (50,9\%\%) artículos reportes de investigación, $14(25,4 \%)$ trabajos de grado 5 (9\%) tesis de maestría, 7 (12,7\%) Trabajo de investigación y 1 (1,8 $\%)$ tesis de doctorado. Para seleccionar y organizar los datos encontrados se 
elaboró una base de datos en Microsoft Access y se almacenaron en las siguientes categorías: autor, año, país, titulo, ubicación, objetivos, problema, enfoque metodológico, enfoque teórico y resultados.

En la segunda fase, la hermenéutica, se analizaron los datos para describir las características de las investigaciones: ámbito de producción, principales temáticas, enfoques teóricos y metodológicos, y los resultados y las tendencias investigativas en el campo de la narración oral. Además, se identificaron y analizaron los aspectos similares y las diferencias notables en los trabajos de investigación revisados.

\section{Resultados}

Se evidenciaron las tendencias temáticas del objeto de investigación, la narración oral en la escuela y la producción investigativa en el ámbito internacional y nacional; también se hallaron tendencias metodológicas, tendencias de los resultados, de lo novedoso y de lo que los tópicos sobre los cuales nada se ha dicho:

- Tendencias Temáticas. Respecto a las temáticas, se encuentran diversos tópicos de estudio acorde con la complejidad del concepto de la narración oral. El tema de mayor interés para los investigadores es la relación entre narración oral y el cuento. De manera específica, en esta relación se aborda: a) como estrategia didáctica (Tamayo, López y Torres, 2009; Arguello, 2013; Martínez, 2011; Real, 2013); b) la cultura, la identidad (Forero, 2012; Zerpa, 2012; Peris, 2014); c) la intervención social (Ardila, 2012); d) lo escénico (Castillo, 2011). En las investigaciones analizadas el cuento es considerado como la estrategia didáctica por excelencia para el desarrollo de la narración oral.

Otras relaciones del estudio de la narración oral son: a) la didáctica (García, 2012; Sbriziolo, 2013; Valbuena y Valbuena, 2012); b) la aplicación en ambientes educativos (Rael, 2009; Fernández, 2012; Tejerina, 2010); c) los aspectos gramaticales (García-Azkoaga y Díaz, 2010; Becerra y Alarcón, 2014; Romero, 2014); d) la historia y la tradición oral (Forero, 2012; Álvarez, 2012; Bolaño y García, 2010); e) lo literario (Jiménez, 2014; Ayala, 2012); f) competencias comunicativas (Patiño y Ramírez, 2011; Segovia, 2012) y g) educación especial (Maggiao, M., Coloma, y Pavez, 2009; Fernández, y Vasco, 2012; Catalán, Montes, Piña, Salazar y San Martin (2011). Las diferentes perspectivas de los acercamientos temáticos de la narración oral, configuran un campo importante para continuar en su indagación. 
- Producción investigativa ámbito internacional. Hay preocupación entre los investigadores por desarrollar experiencias conducentes a articular la narración oral en los procesos educativos del entorno escolar. Se presentan avances en el aspecto metodológico, en países como: España (25,4\%), Venezuela $(12,7 \%)$ y México (9\%). Sin embargo, es relevante cómo este interés investigativo surge de acciones aisladas y unitarias. En la figura 1 se indican los países que han desarrollado investigaciones sobre esta temática durante los últimos cinco años.

Figura 1. Países con producción investigativa en narración oral.

Producción Investigativa Narración Oral. 2009-2014

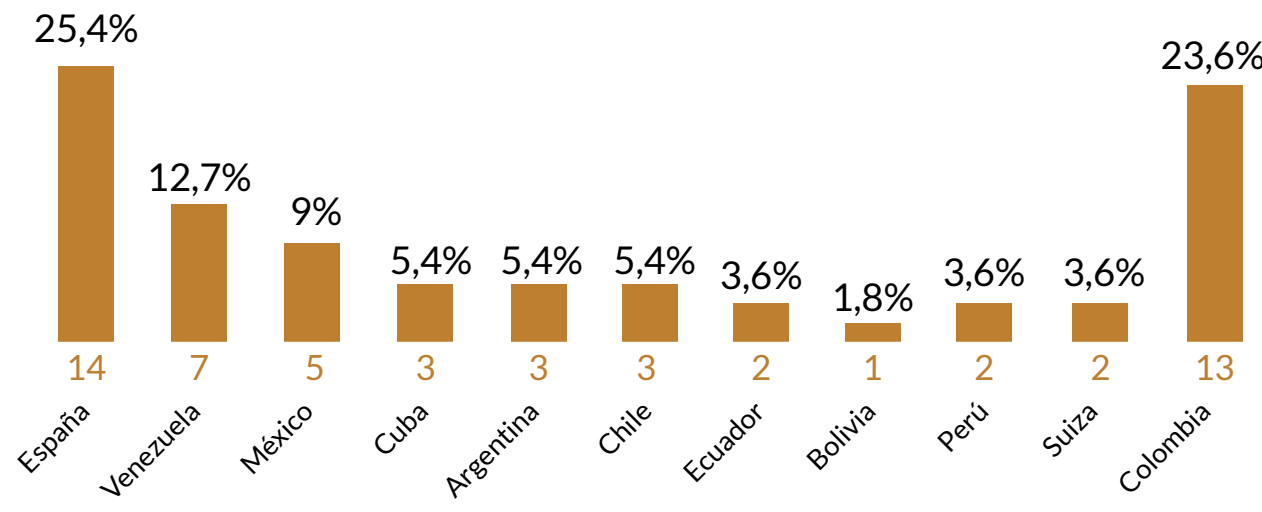

Fuente: elaboración propia

En este panorama, España tiene una importante producción en torno al tema de la narración oral; las investigaciones se enfocan en las dos líneas: la artística y la promoción en la escuela. En la tabla 1 se muestra su producción:

Tabla 1. Investigaciones sobre la narración oral en España

\begin{tabular}{|c|c|c|c|}
\hline Año & Titulo & Autor & $\begin{array}{c}\text { Tipo de } \\
\text { documento }\end{array}$ \\
\hline 2009 & La narración oral en el colegio. & $\begin{array}{c}\text { Rael, Fuster. } \\
\text { M. }\end{array}$ & Artículo \\
\hline 2009 & $\begin{array}{c}\text { La aplicación de la "fantástica" o arte de inventar } \\
\text { historias en la facultad de artes. }\end{array}$ & Algarra, C. V. & Artículo \\
\hline 2010 & $\begin{array}{c}\text { Cohesión en situación de interacción, en caso de la } \\
\text { narración oral. }\end{array}$ & $\begin{array}{c}\text { García- } \\
\text { Azkaga, I. M. } \\
\text { y Díaz, L }\end{array}$ & Artículo \\
\hline 2010 & La narración oral como un arte al alcance de todos & Tejerina, I. & Artículo \\
\hline
\end{tabular}




\begin{tabular}{|c|c|c|c|}
\hline Año & Titulo & Autor & $\begin{array}{c}\text { Tipo de } \\
\text { documento }\end{array}$ \\
\hline 2011 & El cuento como instrumento educativo. & Martínez, N. & Artículo \\
\hline 2012 & $\begin{array}{l}\text { Narración oral de cuentos comunitaria y escena } \\
\text { critica como la herramienta de Intervención social. }\end{array}$ & Ardila, V. J. & $\begin{array}{c}\text { Tesis } \\
\text { doctoral }\end{array}$ \\
\hline 2012 & La narración oral en el aula en educación infantil. & Fernández, R. & $\begin{array}{l}\text { Trabajo de } \\
\text { grado }\end{array}$ \\
\hline 2012 & $\begin{array}{l}\text { La adquisición de la competencia narrativa a } \\
\text { través del cómic en la Escuela Primaria }\end{array}$ & Segovia, B & Artículo \\
\hline 2013 & $\begin{array}{l}\text { La narración oral de cuentos en su relación con el } \\
\text { desarrollo del lenguaje: un proyecto de trabajo }\end{array}$ & Arguello, S. M. & $\begin{array}{l}\text { Trabajo de } \\
\text { grado }\end{array}$ \\
\hline 2013 & $\begin{array}{c}\text { Dispositivo didáctico e intervención docente } \\
\text { para mejorar la producción oral del alumno/a. } \\
\text { intervención en un contexto de inmersión } \\
\text { lingüística en Euskara }\end{array}$ & Zabala A., J. & Artículo \\
\hline 2013 & $\begin{array}{l}\text { La narración oral en la educación secundaria } \\
\text { obligatoria: una propuesta didáctica. }\end{array}$ & Sbriziolo, C. & $\begin{array}{l}\text { Trabajo de } \\
\text { grado }\end{array}$ \\
\hline 2014 & $\begin{array}{l}\text { Estudio de un corpus de narraciones orales que } \\
\text { explican el origen de seudogentilicios. }\end{array}$ & Pascual, C. & $\begin{array}{l}\text { Trabajo de } \\
\text { investigación. }\end{array}$ \\
\hline 2014 & $\begin{array}{l}\text { El giro narrativo en España. Investigación y } \\
\text { formación con enfoques auto/biográfico }\end{array}$ & $\begin{array}{l}\text { González, J. } \\
\text { Ochoa, C. }\end{array}$ & Artículo \\
\hline 2014 & No me cuentes cuentos & Peris R.,B & Artículo \\
\hline
\end{tabular}

Fuente: elaboración propia

De acuerdo con los datos, España está a la vanguardia de la investigación en el ámbito internacional. En el caso español, el interés investigativo por fomentar la narración oral en el aula de clase ha venido en aumento. Busca con ello desarrollar la capacidad comunicativa y creadora de los y las estudiantes; por ejemplo, mediante la creación de cuentos orales y por ende, el impulso a la creatividad como propuesta didáctica en todos los niveles educativos de formación. Se encuentran trabajos relacionados con la promoción de la narración oral y la manera como ésta se aplica en las instituciones de educación primaria (Rael, 2.009; Arguello, 2013; Fernández, 2012; Martínez, 2011). Según las investigaciones, la estrategia pedagógica para fomentar la narración oral básicamente es el cuento (Sbriziolo, 2013; Arguello, 2013; Ardila, 2012; Martínez, 2011).

Para mejorar las destrezas orales de los estudiantes se trabaja la perspectiva interaccionista y sociodiscursiva de la escuela ginebrina en ocho secuencias didácticas (Zabala, 2013). En el ámbito general de la narración se plantea el 
giro de la investigación hacia el enfoque auto/biográfico y hacia modelos más cualitativos, hermenéuticos y narrativos y su concreción a través del uso de los árboles genealógicos en formación y los retos que plantea el análisis sociocultural aplicado a estos materiales biográficos (González y Ochoa, 2014).

Una novedad metodológica es la relación entre la narración oral y lo artístico (Tejerina, 2010). Ardila (2012) con la participación del grupo de teatro la Candelaria de Bogotá, estudia la narración oral y el teatro, con el objetivo de diseñar una propuesta técnica y práctica para materializar la teoría critica en esa expresión artística. Del mismo modo, la promoción de la invención o del arte de contar historias en un espacio como la universidad (Algarra, 2009) y el empleo del cómic para desarrollar la competencia narrativa oral, para promover la educación mediática (Segovia, 2012), son aportes importantes para la didáctica.

Por otra parte, los países de América Latina, y en España, manifiestan interés por la investigación en la narración oral. Sobresalen Colombia, Venezuela y México. Sin embargo, Argentina y Cuba mantienen la tradición investigativa en menor medida. En contraposición, Chile, caracterizado por el desarrollo de la investigación en el continente, no se destaca por el trabajo investigativo de este tema, en el período de estudio.

De manera particular, en Venezuela, las investigaciones están enfocadas en dos aspectos: uno, la narración oral como medio de la promoción de la lectura y el otro, la narración oral como oficio profesional. Se puede apreciar la preocupación por fomentar la lectura a través de la narración oral; los trabajos giran en torno a la lecto-escritura y su transformación a la narración oral como complemento a este proceso de enseñanza (Level, 2009; Escalante, 2009 y Correa, 2009).

Hay motivación por establecer conexiones entre la narración oral y lo artístico a través del vínculo entre la academia y la parte artística en el que las mujeres juegan un papel importante, tal como se aprecia, en la investigación de Zerpa (2012). Un tema emergente es la conexión entre narración oral e identidad (Castillo, 2011; Zerpa, 2012). Otra temática novedosa es la relación de la narración oral con aspectos sintácticos, como es el caso de la investigación de Sánchez y Silva (2009). En general, se manifiestan las tendencias del estudio de la narración oral respecto a la preocupación por las estrategias didácticas en el aula de clases como el cuento, la literatura, los textos escolares y la narración oral escénica. En la tabla 2 se señala la producción de Venezuela: 
Tabla 2. Investigaciones sobre el trabajo de la narración oral en Venezuela.

\begin{tabular}{|c|c|c|c|}
\hline Año & Titulo & Autor & $\begin{array}{l}\text { Tipo de } \\
\text { documento }\end{array}$ \\
\hline 2009 & $\begin{array}{l}\text { El cuento, la lectura y la convivencia como valor } \\
\text { fundamental en la educación inicial. }\end{array}$ & Correa, M. & Artículo \\
\hline 2009 & $\begin{array}{l}\text { Literatura para niños: Una forma natural de } \\
\text { aprender a leer. }\end{array}$ & Escalante, C & Artículo \\
\hline 2009 & Textos escolares: oralidad, lectura y escritura & Level, M & Artículo \\
\hline 2009 & $\begin{array}{l}\text { El empleo de los tiempos verbales en la re- } \\
\text { narración: Un estudio de las producciones orales y } \\
\text { escritas de niños pequeños. }\end{array}$ & $\begin{array}{l}\text { Sánchez, V; } \\
\text { Silva, M. }\end{array}$ & Artículo \\
\hline 2011 & $\begin{array}{c}\text { La narración oral escénica como elemento de } \\
\text { identidad (Tres cuenta cuentos del Estado } \\
\text { Portuguesa). }\end{array}$ & Castillo, J. & $\begin{array}{l}\text { Tesis de } \\
\text { maestría. }\end{array}$ \\
\hline 2012 & $\begin{array}{c}\text { La experiencia en la narración oral, un espacio } \\
\text { para profundizar procesos identitarios con } \\
\text { perspectivas de género. }\end{array}$ & Zerpa, I. & Artículo \\
\hline 2012 & $\begin{array}{c}\text { Mujeres que cuentan y escuchan cuentos. Una } \\
\text { apuesta común. }\end{array}$ & Zerpa, I. & Artículo \\
\hline
\end{tabular}

Fuente: elaboración propia

Los aspectos culturales como la identidad (Castillo, 2011; Zerpa, 2012) y el estudio del género (Zerpa, 2012) emergen como otra corriente de la narración oral. Del mismo modo, la conexión entre literatura y narración oral es otra perspectiva de análisis en el entorno escolar.

Otro país que ha continuado con la investigación en este tópico es México. También se caracteriza por sus aportes, en la educación básica y la secundaria. En la tabla 3 se muestran sus desarrollos:

Tabla 3. Investigaciones sobre la narración oral en México.

\begin{tabular}{|c|c|c|c|}
\hline Año & Titulo & Autor & $\begin{array}{c}\text { Tipo de } \\
\text { documento }\end{array}$ \\
\hline 2009 & $\begin{array}{c}\text { La interacción verbal para el desarrollo de } \\
\text { habilidades expresivas de los niños y niñas. }\end{array}$ & $\begin{array}{c}\text { Ávila, l; } \\
\text { Muñoz, H. }\end{array}$ & Artículo. \\
\hline 2010 & Primero la técnica, después lo demás & Gelos, G & Artículo \\
\hline 2012 & $\begin{array}{c}\text { Los relatos de tradición oral y la problemática de } \\
\text { su descontextualización y su re-significación. }\end{array}$ & Álvarez, G. & $\begin{array}{c}\text { Tesis de } \\
\text { maestría }\end{array}$ \\
\hline
\end{tabular}




\begin{tabular}{|c|c|c|c|}
\hline & Titulo & Autor & $\begin{array}{c}\text { Tipo de } \\
\text { documento }\end{array}$ \\
\hline 2013 & $\begin{array}{c}\text { Desarrollo léxico en la adolescencia: Un análisis de } \\
\text { sustantivos en narraciones orales y escritas }\end{array}$ & Hess Z, K. & Artículo \\
\hline 2014 & $\begin{array}{c}\text { Coordinación y subordinación en la narración oral } \\
\text { de niños y jóvenes del primer y último año en la } \\
\text { escuela básica mexicana. }\end{array}$ & $\begin{array}{c}\text { Becerra, Y. G. } \\
\text { y Alarcón,. }\end{array}$ & $\begin{array}{c}\text { Trabajo de } \\
\text { grado }\end{array}$ \\
\hline
\end{tabular}

\section{Fuente: elaboración propia}

Después de un período de recesión del estudio de la temática, en el último año se volvió a retomar. Una de las investigaciones hace una mirada hacia el interior de la escuela para relacionar al estudiante, considerado punto de referencia, con su entorno social (Ávila y Muñoz, 2009). De la misma forma, hay un acercamiento a la cultura a través de la tradición oral, para buscar la creación de una asignatura de lengua indígena como parte del currículo de la educación básica en México (Álvarez, 2012). Se presenta una reflexión acerca del dominio de los recursos técnicos para ser aplicados en la escuela, de una manera sistemática y coherente (Gelos, 2010). También, el aspecto sintáctico y lexical, es materia de análisis de la narración oral (Becerra y Alarcón, 2014; Hess, 2014).

Por su parte, Cuba y Argentina tienen investigaciones en las que se asumen dos tópicos de análisis: a) la narración oral como un acto comunicativo artístico y b) la narración oral en el aula de clase. En la tabla 4 se indica la producción investigativa de Cuba:

Tabla 4. Investigaciones sobre la narración oral en Cuba

\begin{tabular}{|c|c|c|c|}
\hline Año & Titulo & Autor & $\begin{array}{c}\text { Tipo de } \\
\text { documento }\end{array}$ \\
\hline 2009 & $\begin{array}{c}\text { La enseñanza de la narración oral como cuento: } \\
\text { gradación de perspectivas. }\end{array}$ & $\begin{array}{c}\text { Tamayo, M; } \\
\text { Torres, Fy } \\
\text { López, M. }\end{array}$ & Artículo \\
\hline 2012 & La narración oral como acto de comunicación. & Barba, T.M. M. & Artículo \\
\hline
\end{tabular}

Fuente: elaboración propia 
En Cuba, las investigaciones consultadas continúan la tendencia de otros países al plantear las relaciones de la narración oral con el cuento, la comunicación y lo artístico y, de manera específica, con el aspecto escénico. Buscan su interacción con el contex to de lo pedagógico y la psicología educativa actual. Respecto al papel relevante del profesor, en el proceso de fomentar la creación en la enseñanza- aprendizaje, se continúa con el enfoque semántico comunicativo (Barba, 2012).

En el período de análisis, en Argentina el estudio de la narración oral en la escuela se promovió en menor medida. Los trabajos centran su atención en el análisis de la narración oral como herramienta para mejorar los resultados de la comunicación y la interacción social del estudiante en la escuela primaria. En esta óptica, se continúa con esta tendencia presentada en países como España y Venezuela. En la tabla 6 se indica la producción investigativa de Argentina:

Tabla 6. Investigaciones sobre la narración oral en Argentina

\begin{tabular}{|c|c|c|c|}
\hline Año & Titulo & Autor & $\begin{array}{c}\text { Tipo de } \\
\text { documento }\end{array}$ \\
\hline 2009 & Hablar en la escuela, ¿para qué? ¿Cómo? & Rodríguez, M & Artículo \\
\hline 2010 & $\begin{array}{c}\text { La narrativa en la enseñanza de la historia en } \\
\text { el jardín. Una experiencia de investigación } \\
\text { participativa e interdisciplinaria }\end{array}$ & $\begin{array}{c}\text { Vergara, A. E., } \\
\text { Balbi, M. N. } \\
\text { y Schierloh, } \\
\text { S. B. }\end{array}$ & $\begin{array}{c}\text { Trabajo de } \\
\text { grado }\end{array}$ \\
\hline \multirow{2}{*}{2012} & $\begin{array}{c}\text { La narración oral como recurso en las clases de } \\
\text { idioma: una experiencia práctica en la enseñanza } \\
\text { de español en estudiantes sinohablantes. }\end{array}$ & García, F. & Artículo \\
\hline
\end{tabular}

Fuente: elaboración propia

En Argentina la producción investigativa ha decaído en los últimos años pese a tener un largo proceso en la narración oral y un movimiento nacional muy dinámico. Esto, por el número de festivales y la producción de artículos de narradores profesionales que buscan una forma de expresión artística profesional. En su producción de los últimos años, se evidencia la tendencia presentada en otras investigaciones al recurrir al cuento literario, tradicional o de creación propia como estrategia didáctica (Rodríguez, 2009). Un avance es el estudio metodológico de la narración desde la interdisciplinariedad, para enseñar la historia (Vergara, Balbi y Schierloh, 2010). A la vez, García (2012) presenta una investigación novedosa para enseñar la lengua española a estudiantes de la Universidad de China. 
Igualmente en Chile, país que ha estado a la vanguardia de la investigación, ha decaído la producción investigativa. No enfatiza en el vínculo de la narración oral y la escuela. La perspectiva investigativa se centra en la población adulta y en los educadores. En la investigación de Catalán, Montes, Salazar y San Martín (2.011) con el semillero de la Universidad de Santiago de Chile se aborda el tema de las personas con afasia para hacer una interacción entre la comprensión y asimilación con el discurso narrativo oral. En el mismo interés de los trastornos y la narración oral está el trabajo de Coloma, Maggiolo, Pavez (2013). La conexión entre narración y aspectos de la salud es una novedad, poco investigada en los otros países.

Otra novedad es la apropiación de la historia a través de la tradición oral. En esta perspectiva, es el trabajo de Huerta, Paredes, Guzmán, Cid y Rodríguez (2014) quienes reconstruyen la historia de la escuela Casa Azul a partir de los relatos de tradicional oral en los habitantes de la municipalidad de Yungay. Esta temática también emerge en la Argentina como se expuso anteriormente. En la tabla 7 se señalan dichas investigaciones:

Tabla 7. Investigaciones sobre la narración oral en Chile

\begin{tabular}{|c|c|c|c|}
\hline Año & Titulo & Autor & $\begin{array}{c}\text { Tipo de } \\
\text { documento }\end{array}$ \\
\hline 2011 & $\begin{array}{c}\text { Desempeño en la comprensión del discurso } \\
\text { narrativo oral en las personas sin trastornos de la } \\
\text { comunicación. }\end{array}$ & $\begin{array}{l}\text { Catalán, J; } \\
\text { Montes, D; } \\
\text { Salazar, M \& } \\
\text { San Martín, D }\end{array}$ & $\begin{array}{l}\text { Trabajo de } \\
\text { grado }\end{array}$ \\
\hline 2013. & $\begin{array}{c}\text { Comprensión de narraciones orales en niños con } \\
\text { Trastorno Específico del Lenguaje }\end{array}$ & $\begin{array}{l}\text { Coloma, C.J., } \\
\text { Maggiolo, M., } \\
\text { Pavez, M.M. }\end{array}$ & Artículo \\
\hline 2014 & $\begin{array}{c}\text { Reconstrucción histórica del proceso educativo de } \\
\text { la escuela casa azul en la población Yungay a partir } \\
\text { de la historia oral de los educadores. }\end{array}$ & $\begin{array}{c}\text { Huerta, M, } \\
\text { C; Paredes, } \\
\text { Guzmán, } \\
\text { S; Cid, } \\
\text { Rodríguez, S. }\end{array}$ & $\begin{array}{l}\text { Trabajo de } \\
\text { grado }\end{array}$ \\
\hline
\end{tabular}

\section{Fuente: elaboración propia}

Es importante resaltar la mirada investigativa que se hace desde los educadores como sujetos objeto del análisis y el aporte metodológico de la investigación narrativa de las historias de vida en el enfoque biográfico, que ha adquirido identidad propia en el campo de la investigación cualitativa (Bolívar y Domingo, 2006). 
Otros países como Ecuador, Bolivia, Perú y Suiza han incursionado en la temática con poca producción. Se trabaja en la conexión entre narración y competencias comunicativas de los y las estudiantes. Un ejemplo, es el trabajo de Mercado (2010), en el que las profesoras de una institución educativa utilizan la narración oral como elemento pedagógico y didáctico para desarrollar dichas competencias. Por otra parte, el tema del protagonismo de los profesores como actores objeto de reflexión como se dio en Chile, cobra relevancia en la investigación de Vélez y Vivanci (2014), quienes realizan en un proyecto que ejecutan las integrantes de un colectivo, para exponer sus vivencias y experiencias, a partir de su rol como profesoras y narradoras orales profesionales.

En esta dinámica, otro de los objetivos es la promoción de la narración oral y la tradición oral de leyendas, cuentos e historias para poder preservarlas en el imaginario colectivo de las comunidades (Jemio y López, 2010; Forero, 2009). Mientras que Dolz y Gagnon (2.010) aborda el texto escrito y su traslación al lenguaje oral como una manera de crear en los y las estudiantes su gusto por la lectura. Otro interés es la motivación y el desarrollo de la expresión oral desde los primeros años (Mercado, 2010). También, se realiza un estudio comparativo del discurso oral en comunidades multilingües, como otra visión de su análisis (Sánchez, 2013). En la tabla 8 se indica la producción investigativa de varios países:

Tabla 8. Investigaciones sobre la narración oral en otros países

\begin{tabular}{|c|c|c|c|c|}
\hline Año & País & Titulo & Autor & $\begin{array}{c}\text { Tipo de } \\
\text { documento }\end{array}$ \\
\hline 2009 & Ecuador & $\begin{array}{l}\text { Los cuentos de tradición oral como } \\
\text { mecanismo de transmisión de saberes } \\
\text { ancestrales relacionados con la } \\
\text { naturaleza, en comunidades dela } \\
\text { micro cuenca del rio Chimborazo }\end{array}$ & $\begin{array}{c}\text { Forero } \\
\text { Lozano, J.A. }\end{array}$ & $\begin{array}{c}\text { Trabajo de } \\
\text { grado }\end{array}$ \\
\hline 2014 & Ecuador & $\begin{array}{l}\text { Aplicación de la literatura infantil } \\
\text { y su incidencia en el desarrollo de } \\
\text { la comprensión y expresión oral } \\
\text { de los niños y niñas de primer año } \\
\text { de educación general básica de la } \\
\text { escuela "San José" de la ciudad de } \\
\text { Cariamanga, Cantón Calvas, período } \\
\text { lectivo 2013-2014. Lineamientos } \\
\text { alternativos. }\end{array}$ & Jiménez, C. & $\begin{array}{c}\text { Trabajo de } \\
\text { grado }\end{array}$ \\
\hline 2011 & Bolivia & $\begin{array}{l}\text { Mitos y cuentos de la tradición oral } \\
\text { boliviana }\end{array}$ & $\begin{array}{l}\text { Jemio, L.y } \\
\text { López, D. }\end{array}$ & Libro \\
\hline
\end{tabular}




\begin{tabular}{|c|l|l|c|c|}
\hline \multicolumn{1}{|c|}{ Año } & \multicolumn{1}{|c|}{ Titulo } & Autor & $\begin{array}{c}\text { Tipo de } \\
\text { documento }\end{array}$ \\
\hline 2010 & Suiza & $\begin{array}{l}\text { El género textual una herramienta } \\
\text { didáctica para desarrollar el lenguaje } \\
\text { oral y escrito. }\end{array}$ & $\begin{array}{c}\text { Dolz, J.\& } \\
\text { Gagnon }\end{array}$ & Artículo \\
\hline 2013 & Suiza & $\begin{array}{l}\text { Desarrollo Discursivo en contexto } \\
\text { multilingües: Un estudio contrastivo } \\
\text { de niños bilingües y monolingües. }\end{array}$ & Sánchez. V. & Artículo \\
\hline 2010 & Perú & $\begin{array}{l}\text { Desarrollo de la expresión oral en el } \\
\text { aula de educación inicial. }\end{array}$ & $\begin{array}{c}\text { Justiniani } \\
\text { Mercado, I.M. }\end{array}$ & Artículo \\
\hline 2014 & Perú & $\begin{array}{l}\text { Proyecto mariposa: el arte de los } \\
\text { temas tabú en infancia. }\end{array}$ & $\begin{array}{c}\text { Vélez, M. K; } \\
\text { Vivanci, I. }\end{array}$ & Artículo \\
\hline
\end{tabular}

\section{Fuente: elaboración propia}

Como tendencia, está el propósito desarrollar la narración oral como comunicación y como cultura por el rescate de la tradición oral para conservar la identidad de los pueblos. Es el caso de una investigación testimonial y documental donde se recogen y seleccionan leyendas, tradiciones, ficciones y mitos de comunidades de Bolivia y se transmite el valor estético y estilístico de las narraciones (Jemio y López, 2011).

- Producción investigativa ámbito nacional. En Colombia, la producción de la narración oral $(23,6 \%)$ es asumida como herramienta para mejorar la competencia comunicativa en los y las estudiantes, una de las tendencias de los estudios en este campo. Hay un movimiento hacia lo artístico, siguiendo la tendencia internacional. De acuerdo con el tipo de documentos consultados se evidencia el incentivo dado desde las universidades para el estudio de la problemática relacionada con la narración oral en los pregrados y el énfasis de la investigación en las maestrías. También se evidencia el descenso del interés por esta temática, después de tener una alta producción, durante los años de 2009 y 2012.

Asimismo, se aprecia variedad de tipos de investigación, no solamente en el entorno educativo de la escuela, sino que también hay una mirada de la narración como acto artístico (Suárez, 2009; Villa, 2009; Ayala, 2012). Desde lo educativo, las investigaciones se localizan en la escuela básica primaria y secundaria. Básicamente, éstas abordan la narración oral como estrategia didáctica para desarrollar la competencia comunicativa en los estudiantes (Patiño y Ramírez, 2011; Monsalve, 2009). En la Tabla 9 se indica la producción investigativa del país: 
Tabla 9. Investigaciones sobre la narración oral en Colombia

\begin{tabular}{|c|c|c|c|}
\hline Año & Titulo & Autor & $\begin{array}{l}\text { Tipo de } \\
\text { documento }\end{array}$ \\
\hline 2009 & $\begin{array}{l}\text { Uso de las Tic en la enseñanza, promoción y } \\
\text { comprensión de textos narrativos en grados } 6 \text {. }\end{array}$ & $\begin{array}{l}\text { Moreno, E; } \\
\text { Barbosa, C. }\end{array}$ & $\begin{array}{l}\text { Trabajo de } \\
\text { grado. }\end{array}$ \\
\hline 2009 & $\begin{array}{c}\text { Apuntes sobre las nuevas dinámicas de la } \\
\text { oralidad. Escuchando a "Wang-Fo" en el lenguaje } \\
\text { hipervincular. }\end{array}$ & Díaz, A. & Artículo \\
\hline 2009 & $\begin{array}{c}\text { Desarrollo de las habilidades comunicativas en la } \\
\text { escuela nueva. }\end{array}$ & Monsalve, M & Artículo \\
\hline 2009 & La cuentearía: el nuevo viejo arte escénico. & Villa, R. & $\begin{array}{l}\text { Trabajo de } \\
\text { investigación }\end{array}$ \\
\hline 2009 & $\begin{array}{l}\text { Relación entre el componente gestual y el } \\
\text { componente sintáctico en narraciones orales. }\end{array}$ & Suárez, F. & Artículo \\
\hline 2010 & $\begin{array}{l}\text { Tradicional oral y sincretismo religioso en Guaca- } \\
\qquad \begin{array}{l}\text { mayal. }\end{array}\end{array}$ & $\begin{array}{l}\text { Bolaño, G. F; } \\
\text { García, P. J. }\end{array}$ & $\begin{array}{l}\text { Trabajo de } \\
\text { grado. }\end{array}$ \\
\hline 2011 & El cuento como instrumento educativo. & Martínez, N & Artículo. \\
\hline 2011 & $\begin{array}{c}\text { Desarrollo de la competencia oral a través de la } \\
\text { comunicación de los niños de grado de transición } \\
\text { de las sedes Antonio Girardot y Buenos Aires de } \\
\text { la Institución educativa Agrícola de Cartagena del } \\
\text { Chaira. }\end{array}$ & $\begin{array}{l}\text { Patiño, J; } \\
\text { Ramírez, A. }\end{array}$ & $\begin{array}{l}\text { Trabajo de } \\
\text { grado. }\end{array}$ \\
\hline 2012 & $\begin{array}{l}\text { Dinámicas del reconocimiento en las narraciones } \\
\text { de jóvenes con discapacidad. }\end{array}$ & $\begin{array}{l}\text { Fernández, A; } \\
\text { Vasco, E. }\end{array}$ & $\begin{array}{l}\text { Trabajo de } \\
\text { grado }\end{array}$ \\
\hline 2012 & $\begin{array}{l}\text { Elementos estéticos para una construcción teórica } \\
\text { de la narración oral escénica. }\end{array}$ & Ayala, F. A. & $\begin{array}{l}\text { Tesis de } \\
\text { maestría. }\end{array}$ \\
\hline 2012 & $\begin{array}{c}\text { Evaluación formativa y auténtica de la narración } \\
\text { oral. }\end{array}$ & $\begin{array}{l}\text { Valbuena, E; } \\
\text { Valbuena, N. }\end{array}$ & Artículo. \\
\hline
\end{tabular}

Fuente: elaboración propia

Una temática de interés es el papel que el profesor debe asumi, como encargo social para la construcción de saberes a través de la narración oral (Galiano, 2012). Así también, investigaciones se centran en el desarrollo de la narración oral con el cuento o el género textual como estrategia didáctica (Martínez, 2011). Un tema a señalar es la mirada a los grupos étnicos y la forma de percibir su mundo mediante la narración oral (Bolaños y García, 2010).

Como temáticas novedosas está el tópico de las Tecnologías de la Información y de la Comunicación (TIC) y su relación con la comprensión de textos narrativos 
(Moreno y Barbosa, 2009; Díaz, 2009). Al igual que en Chile, otra temática emergente es la relación de la narración oral en la población con discapacidad (Fernández y Vasco, 2012).

- Tendencias metodológicas. La metodología privilegiada por los investigadores en las investigaciones objeto de análisis, es la cualitativa $(78 \%$ de las investigaciones) en la que se exploran las experiencias de las personas respecto a la narración oral en la vida cotidiana, básicamente en el aula escolar. Tiene como objetivo la observación y descripción de las cualidades de un fenómeno dado, en este caso, la narración oral. Se emplea el enfoque hermenéutico para interpretar y comprender en profundidad la realidad investigada. Los sujetos de investigación son los y las estudiantes de los niveles de educación básica prima y educación básica secundaria, los profesores, las personas con discapacidad y las mujeres. Las técnicas de investigación más empleadas fueron: la observación, la entrevista, la encuesta, pruebas de evaluación y técnicas teatrales. Los instrumentos fueron el cuestionario, las grabaciones de audio y los videos, los cuentos, los relatos de vida, las fotografías, el diario de campo, el análisis de los textos producidos por los participantes en la investigación y la revisión documental. Esta metodología corrobora la tendencia de la investigación en el campo de las humanidades.

- Tendencias de los resultados. Algunos de los resultados de las investigaciones, fueron los siguientes:

3/4. La narración oral de cuentos, aumenta la capacidad para interactuar con el entorno social (Rael, 2009). Por esta razón, la narración oral se convierte actualmente, en gran aliada para los procesos de enseñanza y aprendizaje (Martínez, 2011; Ardila, 2012; Arguello, 2013; Sbriziolo, 2013; Correa, 2009; Zerpa, 2012; Tamayo, Torres y López, 2009; Suárez, 2011 ; Rodríguez, 2009; Forero, 2009; Montoya, 2010; Dolz y Gagnon, 2010). Además, la presentación y narración de cuentos introduce a los niños y niñas: a) al campo de la literatura (Martínez, 2011); b) motiva a la lectura (Correa, 2009) c) mejoramiento de la escritura (Hess, 2014); d) al desarrollo de su creatividad (Sbriziolo, 2013).

3/4. La narración oral es un proceso dinámico que se configura en una situación de interacción entre el narrador y el público interlocutor (Barba, 2012). Se le asigna un valor educativo por su capacidad de propiciar habilidades comunicativas en los niños y niñas, al dar la posibilidad, en situaciones cotidianas, de comprender por sí mismos y con otros, lo que se piensa y luego se habla en voz alta.

3/4. Las relaciones de la narración oral se establecen con la comunicación, el cuento y el acto artístico (Barba, 2012). Desde la comunicación, las estrategias deben estar enfocados en la interacción y la cooperación (Rodríguez, 2009). 
3/4. La narración oral se valora como herramienta pedagógica y didáctica, en particular, como elemento para la transformación crítica de situaciones problemáticas del contexto (García, 2012) y como estrategia para recuperar el pasado (Huerta, Paredes, Guzmán, Cid y Rodríguez, 2014).

3/4. Se da énfasis a la creatividad a partir de la conexión con las realidades cotidianas. Según García-Azkoaga y Díaz (2010), en la narración oral aparecen formas cohesivas que se trasfieren a textos escritos y de cierta manera, hacen visibles los modos de pensar del ser humano. Es decir, la expresión individual que aparentemente aparece aislada, es mediada hacia la cotidianidad. Asimismo, en la escolaridad también se puede lograr la contextualización de asignaturas electivas en el proceso de la narración oral (Zerpa, 2012)

3/4. Otra posibilidad es la conexión entre la narración oral, lo artístico y lo lúdico para generar historias para ser contadas (Algarra, 2009; Tejerina, 2010; Ardila, 2012; Zerpa, 2012; Barba, 2012; García, 2012; Villa, 2009; Suárez, 2009). La propuesta estética para promover la narración oral es el empleo de diversas técnicas escénicas, con mucha afinidad con el teatro (Ardila, 2012).

- Lo novedoso. Como hallazgo, se encontró la posibilidad de relacionar artística y lúdicamente las estrategias didácticas en las que se compaginan los cuentos actuales con los de tradición. Asimismo, emergen temas como: a) las Tecnologías de la Información y Comunicación (TIC) y la narración oral (Moreno y Barbosa, 2009; Díaz, 2009); b) los puentes entre la narración oral y la discapacidad (Fernández y Vasco, 2012; Catalán, Montes, Salazar y San Martín, 2.011).

Una novedad en las estrategias didácticas es la utilización de narración de cuentos para enseñar la lengua española a universitarios chinos (García, 2012). Otra estrategia es el rincón del cuento en el salón de clases; además, se entrelaza esta actividad con la filmación dentro del aula mientras se cuentan los cuentos (Mercado, 2009; Peris, 2014). En otros contextos, como los espacios académicos universitarios, en la modalidad de cátedra se implementan los narradores orales de amplia trayectoria artística (Algarra, 2009). De igual manera, emerge la narración como elemento para resaltar la identidad (Castillo, 2011; Zerpa, 2012) y como ya se mencionó, como estrategia para rescatar los hechos históricos más significativos.

- Lo no dicho. Respecto a lo no dicho en las investigaciones, no hay una pregunta que interrogue acerca del trabajo interdisciplinario y transversal para la inclusión de la narración oral como parte central del currículo y en este mismo sentido, interrogar acerca de la complejidad de su examen pedagógico y didáctico en el ámbito de la escuela. 
Al mismo tiempo, hay ausencia de trabajos investigativos que indaguen acerca de la formación de profesores para fomentar la narración oral en la escuela. En esta línea, no se estudian los referentes teóricos y metodológicos para afrontar y liderar su avance en el aula de clases.

\section{Conclusiones}

La narración oral es un tema que durante los últimos cinco años ha tenido presencia en el campo de la investigación, de manera particular en países como España, Colombia, México y Venezuela. Sin embargo no se puede concluir que su desarrollo sea de manera sostenida y continua.

En las investigaciones analizadas se estudió la narración oral desde varios aspectos: a) Estrategia didáctica, para fomentar entre otros, la competencia comunicativa y la formación integral de los y las estudiantes. El cuento, es la estrategia más empleada en las investigaciones para fomentar la narración oral, además del teatro y el comic; b) cultura, se rescatan las narraciones de cuentos tradicionales, las historias de vida para cimentar los procesos de identidad y valoración de lo cultural; c) estética, se asume la narración oral escénica como expresiva y comunicadora y de importancia en el aula de clases a través del acceso al cuento literario, la creación individual y los aportes del arte escénico como el teatro; d) la historia, desde el enfoque sociocultural, se rescata la historia de hechos importantes a través de la narración oral.

En relación con la metodología, la tendencia es hacia los modelos más cualitativos, hermenéuticos y narrativos.

En lo no dicho, la ausencia de la perspectiva interdisciplinaria y transversal de la narración oral en los currículos para desarrollar las competencias comunicativas y la formación integral de los y las estudiantes.

Igualmente, otro aspecto importante es la carencia de investigaciones acerca de la formación del profesor que le dé aportes teóricos y metodológicos y la reflexión pedagógica y didáctica para asumir la narración oral en el aula de clase como un eje transversal en los currículos escolares. Éstas son perspectivas para el avance de la investigación en esta temática.

Otros tópicos de indagación para cimentar la investigación en el campo de la narración oral son su relación con las Tecnologías de la Información y Comunicación (TIC), los problemas de discapacidad, el género y el fomento de la cultura.

En síntesis las relaciones de la narración oral en el campo de la investigación son, entre otras: el cuento en todas sus modalidades, lo artístico (teatro), la 
historia y el contexto cotidiano para enfatizar en la identidad. Dichas relaciones se constituyen en aportes para su integración en el ámbito de la escuela.

\section{Referencias}

Ardila, V. J. (2012). Narración oral de cuentos comunicativa y escena critica como la herramienta de Intervención social (Tesis de doctorado, inédito) Universidad Pablo de Olavide, Departamento de trabajo social y servicios sociales, España.

Arguello, S. M. (2013). La narración oral de cuentos en relación con el desarrollo del lenguaje (Tesis de grado,inédita). Universidad de Valladolid, España.

Algarra, C. V. (2009). La aplicación de la "Fantástica" o arte de inventar historias en la facultad de artes. (Tesis inédita), Universidad Politécnica de Valencia, España.

Ayala, F. (2012). Elementos estéticos para una construcción teórica de la narración oral escénica. (Tesis de Maestría). Facultad de Ciencias Sociales. Pontificia Universidad Javeriana. Recuperado de http://repository.javeriana.edu.co/ bitstream/10554/5072/1/tesis307.pdf

Ávila, I. y Muñoz, H. (2009). La interacción verbal para el desarrollo de habilidades expresivas de los niños y niñas. Revista Iberoamericana sobre Calidad Eficacia y Cambio en Educación, 7(1), 1-117. Recuperado de http://www.rinace.net/ reice/numeros/arts/vol7num1/Reice,\%207\%281\%29.pdf

Álvarez, G. F. (2012). Los relatos de tradición oral y la problemática de su descontextualización y re-significación en contexto escolar. (Tesis de Maestría). Facultad de Humanidades y Ciencias de la Educación. Universidad Nacional de la Plata, Argentina. Recuperado de http://sedici.unlp.edu.ar/ handle/10915/21946

Barba, T. M. (2012).La narración oral como acto de comunicación.Revista Didasc@ lia: DEٔE, 4, 139-152. Recuperado de http://revistas.ojs.es/index.php/ didasca/article/vien/1139.

Barberis, A. (2015) Narración Oral. Un puente mágico para descubrir el placer de los cuentos y algo más. Recuperado de http://www.cuentacuentos.eu/ teorica/articulos/AliciaBarberisUnpuentemagico.htm 
Becerra, Y. G. y Alarcón, L. J. (2014). Coordinación y subordinación y subordinación en la narración oral de niños y jóvenes del primer y último año en la escuela básica mexicana. Trabajo de grado. Coordinación y subordinación y subordinación en la narración oral de niños y jóvenes del primer y último año en la escuela básica mexicana. Facultad de Lenguas y Letras. Universidad de Querétaro. Recuperado de http://ri.uaq.mx/bitstream/123456789/2061/1/ RIOO0775.pdf

Bolívar, A. y Domingo, J. (2006). La investigación biográfica y narrativa en Iberoamérica: Campos de desarrollo y estado actual. Forum Qualitative Sozialforschung / Forum: Qualitative Social Research, 7(4). Recuperado de http:// www.qualitative-research.net/index.php/fqs/article/view/161/357

Bolaño, G. F. y García, P. J. (2010). Tradicional oral y sincretismo religioso en Guacamayal. (Trabajo de grado, inédita). Universidad Sergio Arboleda, Colombia.

Castillo, J.E. (2011). La narración oral escénica como elemento de identidad (Tres cuenta cuentos del Estado Portuguesa). (Tesis de Maestría). Maestría de Literatura Latinoamericana. Universidad de los Andes. Recuperado de http://tesis.ula.ve/postgrado/tde_busca/arquivo.php? codArquivo $=9200$

Coloma, C.J., Maggiolo, M. y Pavez, M. M. (2013). Comprensión de narraciones orales en niños con Trastorno Específico del Lenguaje Actualidades en Psicología, 27(115), 129-140

Correa, M. (enero, marzo, 2009,). El cuento, la lectura y la convivencia como valor fundamental en la educación inicial. Revista educare, 13(44), 89-98. Recuperado de http://www.redalyc.org/articulo.oa?id=35614571011

Catalán, J; Montes, D; Piña, N; Salazar, M \& San Martin, D. (2011). Desempeño en la comprensión del discurso narrativo oral en las personas sin trastornos de la comunicación. (Tesis de grado). Facultad de Medicina y Audiología. Universidad de Chile. Chile. Recuperado de http://repositorio.uchile. $\mathrm{cl} /$ bitstream/handle/2250/1 14960/desempe\%C3\%B 10\%20en\%20 la\%20comprension $\% 20$ del $\% 2$ odiscurso\%20narrativo\%20oral\%20 en\%20personas\%20sin\%20trastor nos\%20de\%20la\%20comunicacion. pdf? sequence $=1 \&$ is Allowed $=\mathrm{y}$ 
Dolz, J. y Gagnon, R. (2010). El género textual, una herramienta didáctica para desarrollar el lenguaje oral y escrito. Lenguaje, 38(2), 497-527. Recuperado de revistalenguaje.univalle.edu.co/index.php?seccion=REVISTA...446\&download $=1$.

Díaz, A. (2009, Enero, Junio). Apuntes sobre las nuevas dinámicas de la oralidad. Escuchando a "Wang-Fo" en el lenguaje hiper-vincular. Signo y Pensamiento 52(27), 195-205. Recuperado de http/dspace.universis,net/ bitstream/2024/105/1/articulojaveriana.doc..

Escalante, C. (2009). Literatura para niños: Una forma natural de aprender a leer. Revista educare, 12(43). Recuperado de www.scielo.org.ne/scielo. php?hid:s1316_49102008000400028script:sci=arttex.

Forero, L. J. (2009). Los cuentos de tradición oral como mecanismo de transmisión de saberes ancestrales relacionados con la naturaleza en comunidades en el micro cuenca del rio Chimborazo. (Tesis de grado, inédita). Colombia.

Forero, J. A.(2012). Los cuentos de tradición oral como mecanismo de transmisión de saberes ancestrales relacionados con la naturaleza, en comunidades dela micro cuenca del rio Chimborazo. Trabajo de grado. Universidad Politécnica Salesiana. Ecuador. Recuperado de http://dspace.ups.edu.ec/bitstream/123456789/2341/1/ Tesis\%20cuentos\%20JForero.\%20VF.\%2030.SEP.09.\%20Parte\%201.\%20 Antecedentes\%20y\%20capitulos..pdf

Fernández, R. (2012). La narración oral en el aula en educación infantil. (Trabajo de grado). Universidad Internacional de la Rioja, España. Recuperado de http:/ / reunir.unir.net/bitstream/handle/123456789/490/Fernandez. Raquel.pdf? sequence $=1$

Fernández, A y Vasco, E. (2012. Julio). Dinámicas del reconocimiento en las narraciones de jóvenes con Discapacidad. Revista Latinoamericana de Ciencias Sociales, Niñez y Juventud, 10, (1), 467-479. Recuperado de www. redalyc.org/articulo.aa?id; revistaumanizales@cinde.org.co

García, F. (2012). La narración oral como recurso en las clases de idioma: una experiencia práctica en la enseñanza de español en estudiantes sino hablantes. (Trabajo de grado, inédita), Universidad de Anhui, Argentina. 
García-Azkoaga, I. M. y Díaz, L. (2010). Cohesión en situación de interacción, en caso de la narración oral. En Estudios Lingüísticos (pp. 177-194) Lisboa: Ediciones Colibrí. Recuperado de http://www.clunl.edu.pt/resources/ docs/revista/n5_fulltexts/5m\%20ines\%20azkoaga.pdf

Galiano, B. J. (2012). Pensar, hacer y vivir la oralidad. Experiencias compartidas por maestros de educación Inicial. (Tesis de grado, inédita), Universidad Nacional de Colombia, Colombia.

Garzón, F. (2008) Definiciones de la Narración Oral. Gaviotas de azogue, (30), Recuperado de https://docs.google.com/document/d/1QDZwpNSneNrxoBax_toLYrAQarWDKP454JRcNhLuilQ/edit?hl=es\&pli=1

Garzón, F. (1988). La narración oral: lenguaje verbal y lenguajes no verbales. Revista Actuemos, (25)

Garzón, F. (1991). El arte (oral) escénico de contar cuentos.

Gelos, G. (2.010). Primero la técnica, después lo demás. Red Internacional de Cuenta cuentos. México.

González, J. y Ochoa, C. (2014). El giro narrativo en España. Investigación y formación con enfoques auto/biográfico. Revista Mexicana de Investigación Educativa, RMIE, 19(62), 809-829.

Hess, K. (2013). Desarrollo léxico en la adolescencia: Una análisis de sustantivos en narraciones orales y escritas. Actualidades en Psicología, 27(115), 113-127.

Huerta, M., C. Paredes, Guzmán, S., y Rodríguez, S. (2014). Reconstrucción histórica del proceso educativo de la escuela casa azul de la población Tungay a partir de la historia oral de los educadores. (Tesis de grado, inédita). Universidad Académico de Humanismo Cristiano, Chile.

Jemio, L. y López, D. (2012). Mitos y cuentos de la tradición oral boliviana. Recuperado de http://www.universitarios.com.bo/content/diez-librosrecogen-la-esencia-de-la-tradici\%C3\%B3n-oral-boliviana 
Jiménez, C. (2014). Aplicación de la literatura infantil y su incidencia en el desarrollo de la comprensión y expresión oral de los niños y niñas de primer año de educación general básica de la escuela "San José" de la ciudad de Cariamanga, Cantón Calvas, período lectivo 2013-2014. Lineamientos alternativos. (Trabajo de grado). Universidad Nacional de Loja. Recuperado de http://dspace.unl. edu.ec/jspui/bitstream/123456789/7572/1/Mar\%C3\%ADa\%2ODel\%20 Carmen\%20Jim\%C3\%A9nez\%20Tacury.pdf

Justiniani, M. (2014). Desarrollo de la expresión oral en el aula de educación inicial. (Trabajo de investigación), Laboratorio Pedagógico Hope, México.

Level, M. (2009, Marzo). Textos escolares: oralidad, lectura y escritura. Revista educare, 13(44). Recuperado de: educere@ula.ve.

Maggiao, M., Coloma, C.J. y Pavez, M. M. (2009). Estimulación de narración infantil. Revista Cefac, 11(3), 379-388. Recuperado de http://www.profvbetancourt.files.wordpress.com/2010/05/estimulacion-de-narraciones-infantiles.pdf

Martínez, N. (febrero, 2011). El cuento como instrumento educativo. Revista digital innovación y experiencias, 45. Recuperado de ww.csif.es/andalucia/ modulos/modules/mod_ense/revista/pdf/numero_39/natalia_ urbano_O1_or.pdf.

Mercado, J. (2010). Desarrollo de la expresión oral en el aula de educación inicial. (Investigación - Acción), Asociación civil hope holando. Perú.

Montoya, V. (2010) La tradición oral latinoamericana. Recuperado de: www. cuidadseva.com/textos/teoria/hist/montoya2.htm, Chile.

Moreno, E. y Barbosa, C. (2009). Uso de las tics en la enseñanza, promoción y comprensión de textos narrativos en grados 6. (Trabajo de tesis, inédita). Universidad Nacional de Colombia, Colombia.

Monsalve, M. (septiembre, diciembre, 2009,). Desarrollo de las habilidades comunicativas en la escuela nueva. Revista educación y pedagogía, 21(55), 189-210.Recuperado de aprenderenlinea.udea.edu.co/revista/indox,php/ revistaeye/article/viewfil/9766/8975. 
Pascual, C. (2014). Estudio de un corpus de narraciones orales que explican el origen de seudogentilicios. (Trabajo de investigación), Universidad de Alicante. Venezuela.

Patiño, J. y Ramírez, A. (2011). Desarrollo de la competencia oral a través de la comunicación de los niños de grado de transición de las sedes Antonio Girardot y Buenos Aires de la Institución educativa Agrícola de Cartagena del Chaira. (Trabajo de grado). Facultad de Ciencias de la Educación. Universidad de la Amazonia. Recuperado de www.edudistancia.2001.wikispaces.com/ file/view.

Peris, R. B. (2014). No me cuentes cuentos. Foro de Profesores de E/LE, (10), 215-223.

Rael, M.I. (2009). Narración oral en el colegio. Revista digital. Innovación $y$ experiencias educativas, (14) Recuperado de http://www.csi-csif.es/ andalucia/modules/mod_ense/revista/pdf/Numero_14/MARIA\%20 ISABEL_RAEL_2.pdf

Ramírez, N. (2012). La importancia de la narración tradición oral: grupo Coyaima. Revista Científica Guillermo de Ockham, 10, (2). Recuperado de http://investigaciones.usbcali.edu.co/ockham/images/volumenes/ Volumen10N2/vol10n2_10.pdf

Real, L. (2013). La narración oral de cuentos en relación con el desarrollo del lenguaje. (Trabajo de grado). Universidad de Valladolid. Facultad de Educación y Trabajo Social Recuperado de http://uvadoc.uva.es/ handle/10324/8186

Rodríguez, M. (2009). Hablar en la escuela, ¿para qué? ¿Cómo? Revista mime educación, formación inicial, 16(1), 70-83. Recuperado de www.2.minedu. gob.pe/digesutp/formacioninicial.

Romero, C. P. (2014). Estudio de un corpus de narraciones orales que explican el origen de seudogentilicios. Boletín de Literatura Oral, (4), 29-42. Recuperado de http://revistaselectronicas.ujaen.es/index.php/blo/ article/view/758/1180

Sánchez. V. (2013). Desarrollo Discursivo en contexto multilingües: Un estudio contrastivo de niños Bilingües y monolingües. Lengua y Habla, 17. Recuperado de http://erevistas.saber.ula.ve/index.php/lenguayhabla/ article/view/4559 
Sánchez, V. y Silva, M. L. (2009).El empleo de los tiempos verbales en la renarración: Un estudio de las producciones orales y escritas de niños pequeños. Experiencias innovadoras en Bogotá, 21, (32). Recuperado de www. scielo.org.ve/scielo.php?pid=So798-9709009000200006\&scrip $=$ sci_ arttext

Suárez, F. (diciembre, 2009). Relación entre el componente gestual y el componente sintáctico en narraciones Orales. Boletín lingüístico, 32(36), 101-122 Recuperado de: www.redalcy.org/articulo.oa?id=34723240006

Sánchez, M. (2013). La narración oral de cuentos en relación con el desarrollo del lenguaje. (Trabajo grado, inédito). Universidad de Valladodid, España.

Segovia, B. (2012). La adquisición de la competencia narrativa a través del cómic en la Escuela Primaria. Revista Complutense de Educación, 23(2), 375399. Recuperado de http://revistas.ucm.es/index.php/RCED/article/ view/40034/3847 1

Sbriziolo, C. (2013). La narración oral en la educación secundaria obligatoria: una propuesta didáctica. (Trabajo de grado). Máster Universitario en Formación del Profesorado de Educación Secundaria, España.

Tejerina, I. (2010). La narración oral un arte al alcance de todos. Universidad de Cantabria, Recuperado de http://www.cervantesvirtual.com/nd/ ark:/59851/bmcn5951. .

Tamayo, M; Torres F y López, M. (2013). La enseñanza de la narración oral como cuento: Gradación de perspectivas. Universidad de Anhui (CHINA). Recuperado de cedoc.infd.ar/upload/la_enseñanza_de_la_narracion_ oral_en_cuentos.pdf.

Vélez, M y Vivanci, I. (2013). Proyecto mariposa: el arte de los temas tabú en infancia. Proyecto mariposa. Recuperado de: www. Proyectomariposanarracion/ blogpdf.com.

Valbuena, E y Valbuena, N. (2012). Evaluación formativa y auténtica de la narración oral. Revista Udistrital, $17(1)$. Recuperado de http://revistas.udistrital.edu.co/ojs/index.php/enunc/article/view/4229. 
Vergara, A. E; Balbi, M. N y Schierloh, S. B. (2010). La narrativa en la enseñanza de la historia en el jardín. Una experiencia de investigación participativa e interdisciplinaria. Lectura y vida: Revista Latinoamericana de Lectura, 31(1), 78-89. Recuperado de http://www.lecturayvida.fahce.unlp.edu.ar/numeros/a31n1/31_01_Vergara.

Villa, R. (2009). La cuentearía: el nuevo viejo arte escénico. Recuperado de: http:// www.cuentacuentos.eu/teorica/articulos/JotaVillazaLaCuenteria.htm

Zabala A., J. (2013) Dispositivo didáctico e intervención docente para mejorar la producción oral del alumno/a. intervención en un contexto de inmersión lingüistica en Euskara. Recuperado de http://www.academia.edu/5818690/ Dispositivo_did\%C3\%A 1ctico_e_intervenci\%C3\%B3n_docente_para_ mejorar_la_producci\%C3\%B3n_oral_del_alumno_a

Zerpa, I. (2012). La experiencia en la narración oral, un espacio para profundizar procesos identitarios con perspectivas de género. Revista Dire, (3). Recuperado de www.epublications.unilim.fr/reves/dire/332.

Zerpa, I. (2012). Mujeres que cuentan y escuchan cuentos. Una apuesta común. Universidad Central de Venezuela, Venezuela. 